\title{
Clinical Characteristics and Long-term Prognosis of Elderly-Onset Ulcerative Colitis in a Population-Based Cohort in the Songpa- Kangdong District of Seoul, Korea
}

Sang Hyoung Park ${ }^{1}$, Seung Kyu Jeong ${ }^{2}$, Ji Hyun Lee ${ }^{3}$, Kyoung Hoon Rhee ${ }^{4}$, Young-Ho Kim ${ }^{5}$, Sung Noh Hong ${ }^{5}$, Kyung Ho Kim 6 , Seung In Seo ${ }^{6}$, Jae Myung Cha ${ }^{7}$, Sun Yong Park ${ }^{8}$, Hyunju Park', Joo Sung Kim ${ }^{10}$, Jong Pil Im ${ }^{10}$, Hyuk Yoon ${ }^{11}$, Sung Hoon $\mathrm{Kim}^{12}$, Jisun Jang ${ }^{12}$, Jeong Hwan $\mathrm{Kim}^{13}$, Seong O Suh ${ }^{14}$, Young Kyun Kim ${ }^{15}$, Byong Duk $\mathrm{Ye}^{1}$, and Suk-Kyun Yang ${ }^{1}$, on behalf of the Songpa-Kangdong Inflammatory Bowel Disease (SK-IBD) Study Group

${ }^{1}$ Department of Gastroenterology, Asan Medical Center, University of Ulsan College of Medicine, ${ }^{2}$ Department of Surgery, Yang Hospital, ${ }^{3}$ Digestive Endoscopic Center, Seoul Song Do Colorectal Hospital, ${ }^{4}$ Department of Internal Medicine, Hansol Hospital, ${ }^{5}$ Department of Medicine, Samsung Medical Center, Sungkyunkwan University School of Medicine, ${ }^{6}$ Department of Internal Medicine, Kangdong Sacred Heart Hospital, Hallym University College of Medicine, ${ }^{7}$ Department of Internal Medicine, Kyung Hee University Hospital at Gangdong, Kyung Hee University College of Medicine, ${ }^{8}$ Kangdong Seoul Colon and Rectal Surgery, ${ }^{9}$ Department of Gastroenterology, Daehang Hospital, ${ }^{10}$ Department of Internal Medicine and Liver Research Institute, Seoul National University College of Medicine, Seoul, ${ }^{11}$ Department of Internal Medicine, Seoul National University Bundang Hospital, Seongnam, ${ }^{12}$ Department of Internal Medicine, VHS Medical Center, ${ }^{13}$ Department of Internal Medicine, Konkuk University Medical Center, Konkuk University School of Medicine, ${ }^{14}$ Department of Internal Medicine, National Police Hospital, and ${ }^{15} \mathrm{Jamsil}$ Seoul Surgical Clinic, Seoul, Korea

See editorial on page 639.

Article Info

Received September 11, 2020

Revised November 17, 2020

Accepted November 17, 2020

Published online January 22, 2021

\section{Corresponding Author}

Suk-Kyun Yang

ORCID https://orcid.org/0000-0003-2772-2575

E-mail sky@amc.seoul.kr

Sang Hyoung Park, Seung Kyu Jeong, and Ji Hyun Lee contributed equally to this work as first authors.
Background/Aims: We aimed to evaluate the clinical characteristics and long-term prognosis of elderly-onset ulcerative colitis (EOUC) in Korean patients over a 30-year period using a wellestablished population-based cohort in the Songpa-Kangdong district of Seoul, Korea.

Methods: Clinical characteristics and prognosis were compared between two groups: EOUC, defined as UC diagnosed in individuals aged $\geq 60$ years and non-EOUC (N-EOUC), defined as UC diagnosed in individuals aged 18 to 59 years.

Results: We identified 99 patients with EOUC (10.3\%) and 866 patients with N-EOUC (89.7\%) between 1986 and 2015. During the median follow-up of 104.5 months, the overall exposure to medications was comparable between patients with EOUC and N-EOUC ( $p=0.091$ for corticosteroids, $p=0.794$ for thiopurines, and $p=0.095$ for anti-tumor necrosis factor agents). The cumulative risks of disease outcomes were also comparable between patients with EOUC and N-EOUC ( $22.4 \%$ vs $30.4 \%$ for proximal disease extension [ $p=0.351$ ], $11.9 \%$ vs $18.1 \%$ for hospitalization $[p=0.240]$, and $2.3 \%$ vs $1.8 \%$ for colectomy $[p=0.977]$ ) at 10 years after diagnosis. Multivariate Cox regression analysis revealed that corticosteroid use at diagnosis was an independent predictor of proximal disease extension (hazard ratio [HR], 6.216; 95\% confidence interval [Cl], 1.314 to 28.826) and hospitalization (HR, 11.241; 95\% Cl, 3.027 to 41.742$)$ in patients with EOUC.

Conclusions: In this population-based study from Korea, the pattern of medication use seemed comparable between the EOUC and N-EOUC groups. Moreover, patients with EOUC and those with N-EOUC have a similar disease course in terms of proximal disease extension, hospitalization, and colectomy. (Gut Liver 2021;15:742-751)

Key Words: Colitis, ulcerative; Aged; Prognosis; Korea

\section{INTRODUCTION}

Ulcerative colitis (UC) is a subtype of inflammatory bowel disease (IBD), which is a chronic inflammatory con- dition of the intestine. ${ }^{1}$ The incidence and prevalence of IBD are continuously increasing in the Western world and are also rapidly increasing in newly industrialized countries, making IBD a global disease. ${ }^{2}$ As the population con- 
tinues to age, the incidence and prevalence of elderly-onset (EO)-IBD, defined as the diagnosis of IBD in patients aged $\geq 60$ years, are expected to increase continuously. ${ }^{3}$ We previously reported an epidemiological study using a well-established population-based cohort in the SongpaKangdong district of Seoul, Korea, which revealed that the incidence of UC has rapidly increased between 1986 and 2015. In this study, we observed a bimodal distribution in the age at diagnosis of IBD, specifically UC, at the age of 60 to 69 years. ${ }^{4}$ This finding seems comparable to those of several Western reports, which showed a second peak in incidence at approximately 60 years of age for IBD, probably due to the aging cohorts in these regions. ${ }^{5-7}$

EO-IBD usually tends to be treated conservatively with consideration of frequent comorbidities. ${ }^{8,9}$ Moreover, chronic corticosteroid use or biologic therapies may result in higher risk of serious opportunistic infections and malignancies in this subset of patients than in younger patients. ${ }^{10,11}$ However, whether or not the natural history and clinical outcomes of elderly-onset ulcerative colitis (EOUC) are different from those of non-EOUC (N-EOUC) remains controversial. Previous studies have suggested that patients with EOUC may have an aggressive disease course, such as higher probabilities of colectomy, compared to those with N-EOUC. ${ }^{12-14}$ Also, recent multicenter studies from Hong Kong reported the poor outcomes of EO-IBD. ${ }^{15,16}$ However, these studies used a referral center-based design, resulting in an inherent risk of referral bias. Additionally, a recent systematic review of a Western population-based cohort showed that EOUC patients have a comparable risk of colectomy as those with N-EOUC. ${ }^{17}$ To date, there has been a paucity of data regarding the long-term characteristics of EOUC in a population-based level from Asian region. We, therefore, aimed to investigate the long-term outcome of EOUC in Korean patients over a 30-year period using a well-defined population-based cohort in Korea.

\section{MATERIALS AND METHODS}

\section{Study patients}

The Songpa-Kangdong IBD study was conducted in the Songpa-Kangdong district, a well-established administrative region in Seoul, Korea, between 1986 (the year of the first IBD diagnosis) and 2015. ${ }^{4}$ This study protocol was approved by the institutional review boards of all involved hospitals and the Songpa-Kangdong IBD cohort is registered in ClinicalTrial.gov (NCT01731665). In this study, the informed consent was waived by the institutional review boards.

\section{Study design}

Based on data from previous studies, ${ }^{15,16,18,19}$ patients with EOUC were defined as those aged $\geq 60$ years at UC diagnosis. The clinical features and disease outcome of patients with EOUC were compared with those with $\mathrm{N}$ EOUC, defined as those aged between 18 and 59 years at UC diagnosis. We gathered the information regarding patients' baseline characteristics, such as sex, age at the time of UC diagnosis, date of UC diagnosis, interval from symptom onset to diagnosis, smoking status at the time of diagnosis, family history of IBD, and disease extent of $\mathrm{UC}$ at diagnosis. Additionally, we investigated the rates of medication use for UC, clinical remission, disease relapse, proximal disease extension on endoscopy, and colectomy during the follow-up period to evaluate subsequent disease progression. The diagnosis of UC was based on a combination of conventional clinical, endoscopic, radiologic, and histopathologic criteria. ${ }^{20}$ The definitions used in this study, including those for disease extent, proximal disease extension, remission, and relapse, have been described in our previous study. ${ }^{21}$ Proximal disease extension was defined as the proximal extension of endoscopic inflammation beyond the initially involved segments (i.e., from proctitis [E1] to left-sided [E2] or extensive colitis [E3], from left-sided colitis [E2] to extensive colitis [E3]). ${ }^{21}$ The use of corticosteroids at UC diagnosis was defined as the commencement of these drugs within a month of UC diagnosis. ${ }^{21}$ Hospitalization was defined as admission for managing flare-ups of UC, either medically or surgically. We excluded admissions that were only for disease evaluation or drug administration, as well as those that were shorter than 3 days or unrelated to UC. ${ }^{22,23}$

\section{Treatment strategy}

In Korea, the treatment strategies for UC patients are not different from those in Western countries and have been previously explained in detail. ${ }^{21}$ Basically, a step-up approach was the mainstay of treatment, and more potent drugs were administered in case patients were refractory to, or intolerant of, first-line therapies. ${ }^{24}$ In general, the strategies for treating EOUC did not differ from those for treating N-EOUC in Korea. ${ }^{13}$ Patients were followed up regularly, usually every 1 to 3 months, depending on their conditions and based on the physicians' discretion. Endoscopy timing and interval were determined for each patient at the physicians' discretion.

\section{Statistical analysis}

Continuous variables are showed as medians and interquartile ranges (IQRs), whereas categorical parameters are showed as numbers and percentages. The t-tests were 
performed to compare continuous variables, and the chisquare tests were used to compare categorical variables. Cumulative risks of medication use for UC, clinical remission, disease relapse, proximal disease extension, hospitalization, and colectomy were calculated with the KaplanMeier methods, and the values were compared between groups with the log-rank tests. Multivariate Cox regression analyses with the stepwise selection methods were used to investigate significant risk factors of the cumulative probabilities of proximal disease extension, hospitalization, and colectomy and to calculate hazard ratios (HRs) and $95 \%$ confidence intervals (CIs). A p-value of $<0.05$ was considered statistically significant. Statistical analysis was performed using the SPSS 21.0 for Windows (IBM Corp., Armonk, NY, USA).

\section{RESULTS}

\section{Baseline characteristics}

One thousand and thirteen patients who were diagnosed with UC between January 1986 and December 2015 were included in this study. ${ }^{4}$ After excluding 48 patients who were diagnosed with UC before the age of 18 years, we included a total of 99 (10.3\%) and $866(89.7 \%)$ patients who were diagnosed with EOUC and N-EOUC, respectively. The baseline features of patients with EOUC and N-EOUC are shown in Table 1. The proportion of men was significantly higher in the EOUC group than in the N-EOUC group ( $\mathrm{p}=0.009$ ) (Table 1). Furthermore, the proportion of current smokers was lower in the EOUC group than in the N-EOUC group ( $<<0.001)$, and the duration of follow-up after the diagnosis of UC was shorter in the EOUC group than in the N-EOUC group $(\mathrm{p}<0.001)$ (Table 1).

\section{Medical treatment}

At diagnosis and/or during the follow-up of median 89.5 months (IQR, 54.3 to 125.9 months), systemic corticosteroids (excluding topical corticosteroid therapy), thiopurines, and anti-tumor necrosis factor (TNF) agents were administered to $30.3 \%, 12.1 \%$, and $8.1 \%$ of patients with EOUC, respectively (Table 1). The median intervals from UC diagnosis to medication initiation were 13.5 months (IQR, 0.5 to 26.1 months) for corticosteroids, 24.4 months (IQR, 10.7 to 60.1 months) for thiopurines, and 36.7 months (IQR, 28.2 to 47.8 months) for anti-TNFs in patients with EOUC. The cumulative risks of medication initiation at 1,5 , and 10 years after UC diagnosis were $15.3 \%$, $32.2 \%$, and $32.2 \%$, respectively, for corticosteroids; $4.1 \%$, $9.9 \%$, and $13.4 \%$, respectively, for thiopurines; and $0.0 \%$, $6.5 \%$, and $8.0 \%$, respectively, for anti-TNFs in patients with EOUC (Fig. 1). The cumulative risks of medication use were not different between EOUC and N-EOUC groups ( $\mathrm{p}=0.091$ for corticosteroids, $\mathrm{p}=0.794$ for thiopurines, and $\mathrm{p}=0.095$ for anti-TNFs) (Fig. 1). Fourteen patients (1.6\%) in N-EOUC and none in EOUC received cyclosporine during the study period. One patient $(0.1 \%)$ in N-EOUC and none in EOUC received vedolizumab during the follow-up.

Table 1. Baseline Characteristics of the Study Patients

\begin{tabular}{|c|c|c|c|c|}
\hline Clinical characteristics & Total & EOUC & N-EOUC & p-value \\
\hline No. of patients & 965 (100) & 99 (10.3) & 866 (89.7) & \\
\hline Male sex & 514 (53.3) & 65 (65.7) & 449 (51.8) & 0.009 \\
\hline Age at UC diagnosis, yr & $37(28-49)$ & $66(62-68)$ & 35 (27-44) & $<0.001$ \\
\hline Interval from onset to UC diagnosis, mo & $2.8(1.0-9.4)$ & $2.0(0.7-7.0)$ & $3.0(1.1-9.8)$ & 0.477 \\
\hline Smoking status at UC diagnosis & & & & $<0.001$ \\
\hline Non-smoker & $508(52.6)$ & $47(47.5)$ & $461(53.2)$ & \\
\hline Former smoker & $161(16.7)$ & $36(36.4)$ & $125(14.4)$ & \\
\hline Current smoker & 153 (15.9) & $8(8.1)$ & 145 (16.7) & \\
\hline Disease extent at UC diagnosis & & & & 0.411 \\
\hline Proctitis & $536(55.5)$ & $61(61.6)$ & 475 (54.8) & \\
\hline Left-sided colitis & $216(22.4)$ & $18(18.2)$ & $198(22.9)$ & \\
\hline Extensive colitis & $213(22.1)$ & $20(20.2)$ & 193 (22.3) & \\
\hline Family history & $44(4.6)$ & $5(5.1)$ & $39(4.5)$ & 0.805 \\
\hline Duration of follow-up, mo & $104.5(60.3-168.7)$ & $89.5(54.3-125.9)$ & $106.2(62.0-172.4)$ & $<0.001$ \\
\hline \multicolumn{5}{|l|}{ Ever use of medications } \\
\hline Systemic corticosteroids & $377(39.1)$ & 30 (30.3) & $347(40.1)$ & 0.059 \\
\hline Thiopurines & 124 (12.8) & $12(12.1)$ & 112 (12.9) & 0.819 \\
\hline Anti-TNFs & 56 (5.8) & 8 (8.1) & 48 (5.5) & 0.306 \\
\hline
\end{tabular}

Data are presented as number (\%) or median (interquartile range).

EOUC, elderly-onset ulcerative colitis; N-EOUC, non-EOUC; UC, ulcerative colitis; TNF, tumor necrosis factor. 

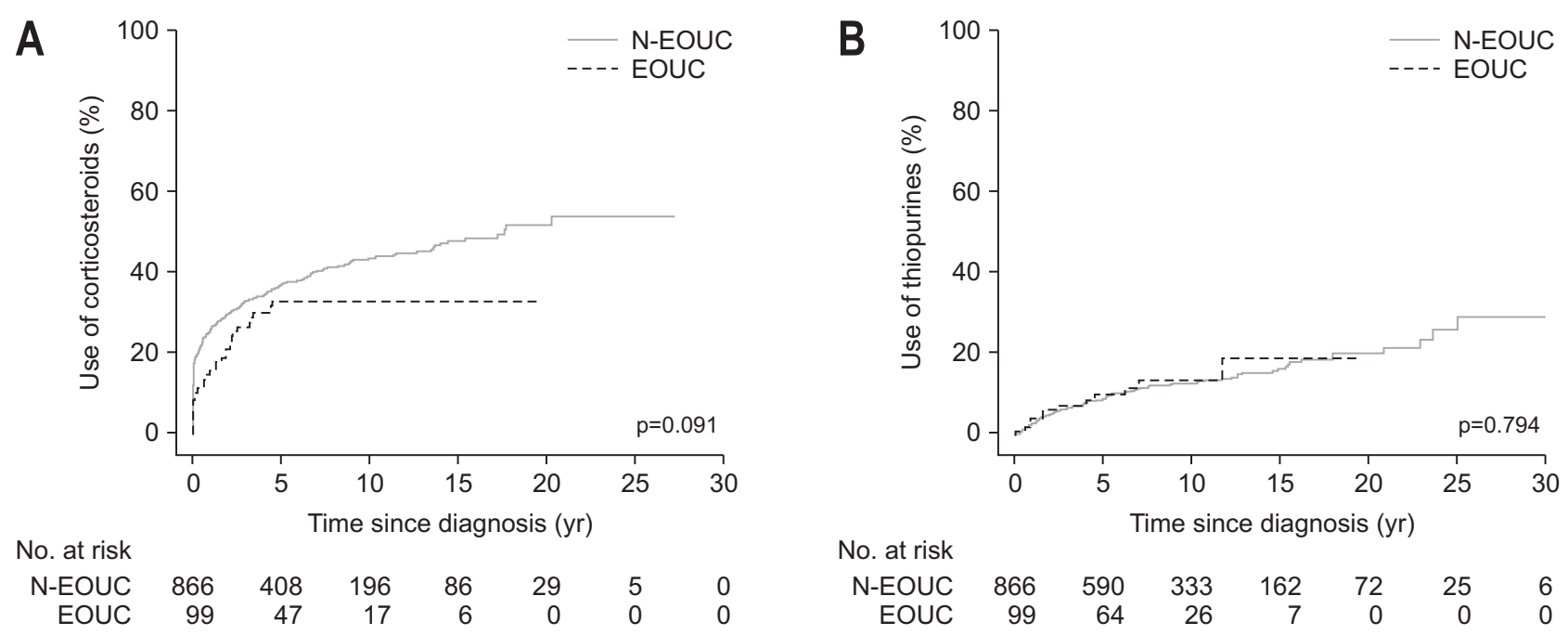

$\begin{array}{rrrrrrrr}\text { No. at risk } & & & & & & \\ \text { N-EOUC } & 866 & 590 & 333 & 162 & 72 & 25 & 6 \\ \text { EOUC } & 99 & 64 & 26 & 7 & 0 & 0 & 0\end{array}$

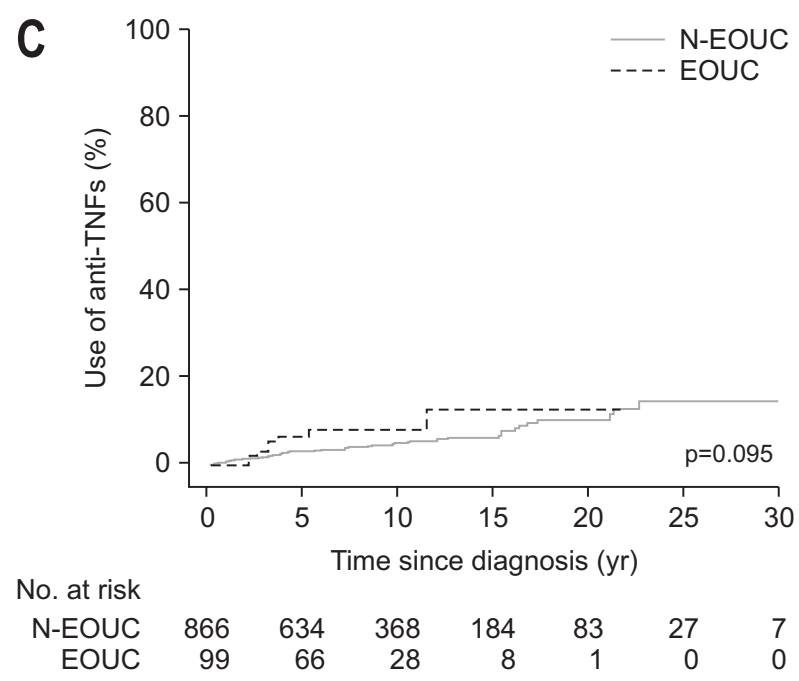

Fig. 1. Cumulative risk of medication use in patients with elderly-onset ulcerative colitis (EOUC) and non-EOUC (N-EOUC): (A) corticosteroids, (B) thiopurines, and (C) anti-tumor necrosis factor (TNF) agents.

\section{Remission}

Among the 99 patients in the EOUC group, 87 patients $(87.9 \%)$ achieved clinical remission. Remission was not reported in seven patients $(7.1 \%)$. The cumulative rates of remission at 1,5 , and 10 years after UC diagnosis were $80.4 \%, 93.0 \%$, and $93.0 \%$, respectively. The cumulative remission rates were not different between the EOUC and N-EOUC patients $(\mathrm{p}=0.348)$.

\section{Proximal disease extension on endoscopy}

In EOUC, endoscopic disease extent at UC diagnosis was divided as proctitis (E1) in 61 cases (61.6\%), left-sided colitis (E2) in 18 cases (18.2\%), and extensive colitis (E3) in 20 cases $(20.2 \%)$. The proportions of patients with $\mathrm{E} 1$, $\mathrm{E} 2$, and $\mathrm{E} 3$ at UC diagnosis were not different between the EOUC and N-EOUC patients ( $\mathrm{p}=0.199, \mathrm{p}=0.290$, and $\mathrm{p}=0.636$, respectively). Of 79 cases with EOUC with E1 or
E2 at UC diagnosis, proximal disease extension was identified in 17 (21.5\%; 16 cases with E1 and one patient with E2) patients, with a median time to proximal extension of 36.6 months (IQR, 23.0 to 61.3 months). The cumulative risks of proximal disease extension after 1,10 , and 15 years were $16.5 \%, 22.4 \%$, and $31.8 \%$ respectively, in 79 patients with EOUC with E1 or E2 at UC diagnosis (Fig. 2A). The cumulative risks of proximal disease extension were comparable between the EOUC and N-EOUC groups $(\mathrm{p}=0.351)$ (Fig. 2A). Even after controlling the differences of baseline characteristics such as sex and smoking status in a multivariate Cox regression analysis, EOUC was not a significant predictive factor for proximal disease extension (HR, 0.699; 95\% CI, 0.422 to 1.156; $\mathrm{p}=0.163$ ). In patients with EOUC, multivariate analysis showed that corticosteroid use at UC diagnosis (HR, 6.216; 95\% CI, 1.314 to 28.826 ) was an independent predictor of proximal disease extension (Table 2). 


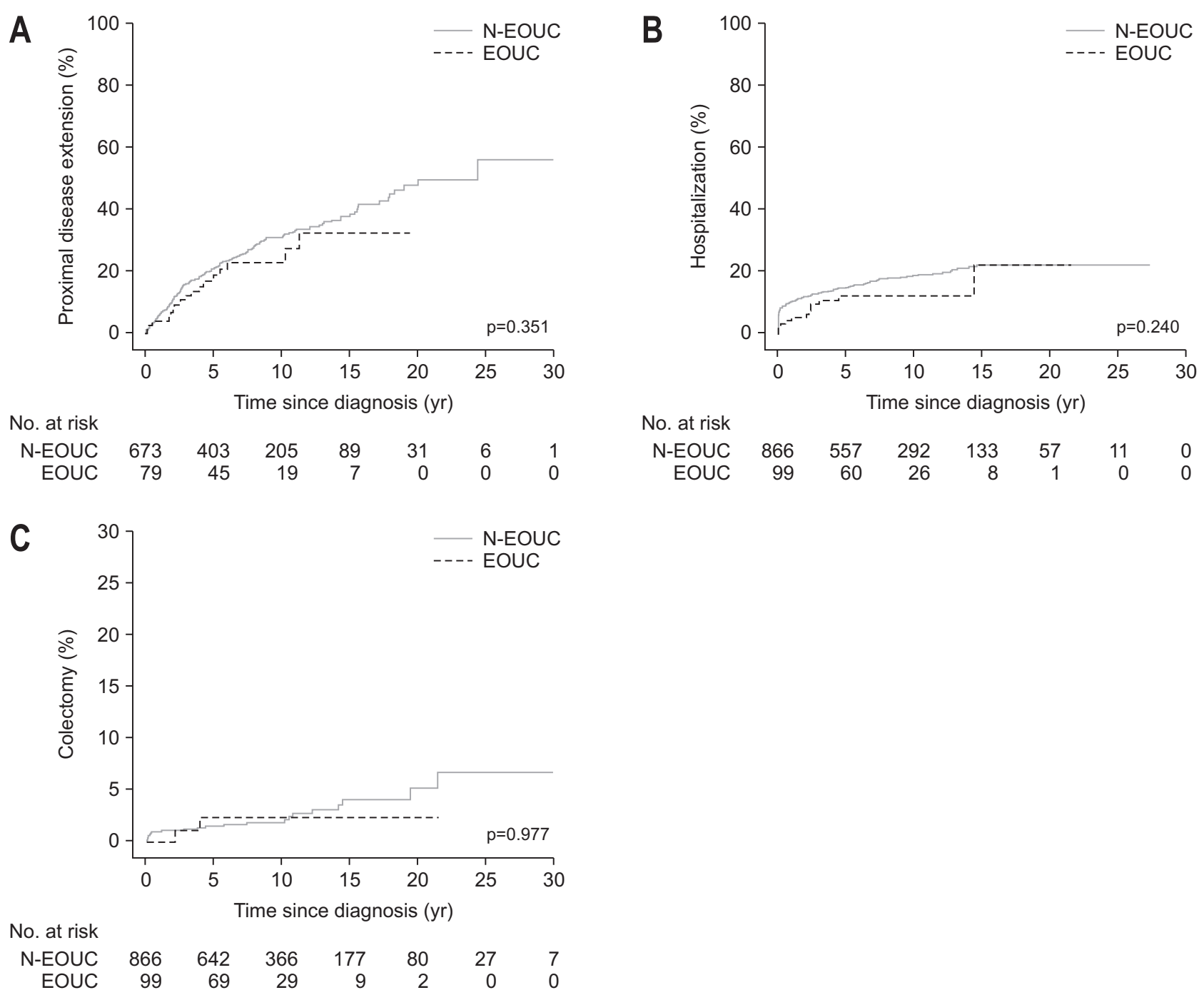

Fig. 2. Cumulative risk of disease outcomes in patients with elderly-onset ulcerative colitis (EOUC) and non-EOUC (N-EOUC): (A) proximal disease extension, (B) hospitalization, and (C) colectomy.

\section{Hospitalization}

Among the 99 patients with EOUC, a total of 12 patients (12.1\%) had histories of at least one hospitalization that required the administration of systemic steroids, immunomodulators, or anti-TNFs or colectomy at UC diagnosis or during the follow-up. The median number of hospitalizations per patient was 1 (IQR, 1 to 2 ), and the median interval from UC diagnosis to the first hospitalization was 29.3 months (IQR, 14.9 to 55.6 months). The cumulative risks of hospitalization at 1,5 , and 10 years after diagnosis were $5.1 \%, 11.9 \%$, and $11.9 \%$, respectively (Fig. 2B). The cumulative risk of hospitalization was not different between the EOUC and N-EOUC patients $(\mathrm{p}=0.240)$ (Fig. 2B). Even after controlling the differences of baseline characteristics such as sex and smoking status in a multivariate Cox regression analysis, EOUC was not a significant predictive factor for hospitalization (HR, 0.688;
95\% CI, 0.379 to 1.251; $\mathrm{p}=0.220$ ). In patients with EOUC, multivariate analysis showed that corticosteroid use at UC diagnosis (HR, 11.241; 95\% CI, 3.027 to 41.742 ) was an independent predictor of hospitalization (Table 3 ).

\section{Colectomy}

Of the 99 patients with EOUC, two cases (2.0\%) underwent colectomy during the follow-up. The reasons for colectomy were medical refractoriness despite maximum medical therapy in one patient (total colectomy with permanent ileostomy) and perforation in one patient (subtotal colectomy with Hartmann closure). The cumulative risks of colectomy at $1,5,10$, and 20 years after UC diagnosis were $0.0 \%, 2.3 \%, 2.3 \%$, and $2.3 \%$, respectively (Fig. 2C). The cumulative risk of colectomy was comparable between the EOUC and N-EOUC groups ( $\mathrm{p}=0.977$ ) (Fig. 2C). Even after controlling the differences of baseline characteristics 
Table 2. Factors for Proximal Disease Extension in Patients with Elderly-Onset Ulcerative Colitis

\begin{tabular}{|c|c|c|c|c|}
\hline \multirow{2}{*}{ Factor } & \multicolumn{2}{|c|}{ Univariate analysis } & \multicolumn{2}{|c|}{ Multivariate analysis } \\
\hline & Hazard ratio $(95 \% \mathrm{Cl})$ & $p$-value & Hazard ratio $(95 \% \mathrm{Cl})$ & p-value \\
\hline \multicolumn{5}{|l|}{ Sex } \\
\hline Female & Reference & & Not included & \\
\hline Male & $0.752(0.286-1.977)$ & 0.563 & & \\
\hline \multicolumn{5}{|c|}{ Smoking status at UC diagnosis } \\
\hline Non-smoker & Reference & & Not included & \\
\hline Former smoker & 0.000 & 0.986 & & \\
\hline Current smoker & $0.772(0.285-2.090)$ & 0.610 & & \\
\hline \multicolumn{5}{|l|}{ Family history of IBD } \\
\hline No & Reference & & Not included & \\
\hline Yes & $0.825(0.109-6.256)$ & 0.852 & & \\
\hline \multicolumn{5}{|c|}{ Disease extent at UC diagnosis } \\
\hline Proctitis & Reference & & Reference & \\
\hline Left-sided colitis & $0.198(0.026-1.498)$ & 0.117 & $0.164(0.021-1.271)$ & 0.084 \\
\hline \multicolumn{5}{|c|}{ Use of corticosteroids at UC diagnosis } \\
\hline No & Reference & & Reference & \\
\hline Yes & 4.409 (0.989-19.662) & 0.052 & $6.216(1.341-28.826)$ & 0.020 \\
\hline
\end{tabular}

$\mathrm{Cl}$, confidence interval; UC, ulcerative colitis; IBD, inflammatory bowel disease.

Table 3. Factors for Hospitalization in Patients with Elderly-Onset Ulcerative Colitis

\begin{tabular}{|c|c|c|c|c|}
\hline \multirow{2}{*}{ Factor } & \multicolumn{2}{|c|}{ Univariate analysis } & \multicolumn{2}{|c|}{ Multivariate analysis } \\
\hline & Hazard ratio $(95 \% \mathrm{Cl})$ & $\mathrm{p}$-value & Hazard ratio $(95 \% \mathrm{Cl})$ & $\mathrm{p}$-value \\
\hline \multicolumn{5}{|l|}{ Sex } \\
\hline Female & Reference & & Not included & \\
\hline Men & $0.523(0.168-1.625)$ & 0.262 & & \\
\hline \multicolumn{5}{|c|}{ Smoking status at UC diagnosis } \\
\hline Non-smoker & Reference & & Not included & \\
\hline Former smoker & $0.649(0.080-5.263)$ & 0.685 & & \\
\hline Current smoker & $0.519(0.138-1.959)$ & 0.333 & & \\
\hline \multicolumn{5}{|l|}{ Family history of IBD } \\
\hline No & Reference & & Not included & \\
\hline Yes & $0.045(0.000-1,672.382)$ & 0.563 & & \\
\hline \multicolumn{5}{|c|}{ Disease extent at UC diagnosis } \\
\hline Proctitis & Reference & & Not included & \\
\hline Left-sided colitis & $0.615(0.074-5.150)$ & 0.615 & $0.501(0.059-4.272)$ & 0.527 \\
\hline Extensive colitis & $3.340(0.974-11.456)$ & 0.055 & $1.844(0.490-6.935)$ & 0.365 \\
\hline \multicolumn{5}{|c|}{ Use of corticosteroids at UC diagnosis } \\
\hline No & Reference & & Reference & \\
\hline Yes & $13.406(3.990-45.037)$ & $<0.001$ & $11.241(3.027-41.742)$ & $<0.001$ \\
\hline
\end{tabular}

$\mathrm{Cl}$, confidence interval; UC, ulcerative colitis; IBD, inflammatory bowel disease.

such as sex and smoking status in a multivariate Cox regression analysis, EOUC was not a significant predictive factor for colectomy (HR, 0.888 ; 95\% CI, 0.203 to 3.887; $\mathrm{p}=0.875$ ). In EOUC, no significant independent predictor of colectomy was identified in the multivariate Cox regression analysis (Table 4).

\section{DISCUSSION}

In the present study, we investigated the long-term outcomes of EOUC in Korea using the well-established population-based cohort. The most notable finding of the current population-based study is that the cumulative rates of colectomy did not differ significantly between patients with EOUC and N-EOUC ( $p=0.817)$. This result seems comparable to the results of previous Western populationbased studies. ${ }^{7,17,19,25}$ Meanwhile, referral center-based studies from both Western and Eastern countries showed higher cumulative rates of colectomy in the EOUC group than in the N-EOUC group. ${ }^{12-14}$ Also, recent multicenter studies from Hong Kong showed that EO-IBD patients had 
Table 4. Factors for Colectomy in Patients with Elderly-Onset Ulcerative Colitis

\begin{tabular}{|c|c|c|c|c|}
\hline \multirow{2}{*}{ Factor } & \multicolumn{2}{|l|}{ Univariate analysis } & \multicolumn{2}{|c|}{ Multivariate analysis } \\
\hline & Hazard ratio $(95 \% \mathrm{CI})$ & $\mathrm{p}$-value & Hazard ratio $(95 \% \mathrm{Cl})$ & $\mathrm{p}$-value \\
\hline \multicolumn{5}{|l|}{ Sex } \\
\hline Female & Reference & & Not included & \\
\hline Male & $0.535(0.033-8.559)$ & 0.659 & & \\
\hline \multicolumn{5}{|c|}{ Smoking status at UC diagnosis } \\
\hline Non-smoker & Reference & & Not included & \\
\hline Former smoker & $1.380(0.085-22.100)$ & 0.820 & & \\
\hline Current smoker & 0.000 & 0.994 & & \\
\hline \multicolumn{5}{|l|}{ Family history of IBD } \\
\hline No & Reference & & Not included & \\
\hline Yes & $21.754(0.000-2.740 E+13)$ & 0.828 & & \\
\hline \multicolumn{5}{|c|}{ Disease extent at UC diagnosis } \\
\hline Proctitis & Reference & & Not included & \\
\hline Left-sided colitis & $0.336(0.021-5.366)$ & 0.440 & & \\
\hline Extensive colitis & 0.000 & 0.987 & & \\
\hline \multicolumn{5}{|c|}{ Use of corticosteroids at UC diagnosis } \\
\hline No & Reference & & Reference & \\
\hline Yes & $10.856(0.675-174.542)$ & 0.092 & $5.822(0.134-253.684)$ & 0.360 \\
\hline \multicolumn{5}{|l|}{ Ever use of medications } \\
\hline Systemic corticosteroids & $2.121(0.133-33.920)$ & 0.595 & Not included & \\
\hline Thiopurines & $7.387(0.461-118.274)$ & 0.158 & $2.606(0.060-113.127)$ & 0.619 \\
\hline Anti-TNFs & $0.043(0.000-126,027,425.000)$ & 0.778 & Not included & \\
\hline
\end{tabular}

$\mathrm{Cl}$, confidence interval; UC, ulcerative colitis; IBD, inflammatory bowel disease; TNF, tumor necrosis factor.

a higher risk of infection, cancer, and hospitalization..$^{15,16}$ Although the cause of this discrepancies among results is unclear, differences in the study design (referral centerbased vs population-based) may play a critical role.

Regarding medical treatment, the cumulative rates of the initiation of medications, including corticosteroids, thiopurines, and anti-TNFs, were similar between the two groups in our study. These results are in contrast with those of previous studies from Western countries, which reported that the cumulative use of steroids is comparable between the EOUC and N-EOUC groups, whereas immunomodulators such as thiopurines and biologics are used less frequently in the EOUC group than in the N-EOUC group. ${ }^{7,17,25,26}$ The reason for this difference in the pattern of medication use between Korean and Western patients with EOUC is unclear. It may be partly explained by the differences in the attitudes of physicians and patients to chronic medication exposure because immunosuppressants are usually avoided for long-term use in elderly patients due to the increased risk of side effects, such as infection and malignancies. ${ }^{10,11}$ Additionally, cultural preferences in Asian regions, such as the use of Eastern medicine or Confucianism, may contribute to the difference in results regarding medical therapy between this study and Western studies. ${ }^{27}$

It is likely that the comparable cumulative rates of the use of disease-modifying drugs, including immunomodulators or anti-TNFs, between patients with EOUC and N-
EOUC may be a contributing factor to the comparable colectomy rate between the two groups; this is in contrast to the higher rate of colectomy in patients with EOUC than in patients with N-EOUC, as demonstrated by previous hospital-based studies including our previous study. ${ }^{12,13}$ To date, there have been conflicting data regarding age as a sole significant factor for the risk of opportunistic infection in patients with IBD receiving immunosuppressants. Although EOUC usually tends to be treated conservatively with the consideration of frequent comorbidities, in a recent post hoc analysis of the randomized evaluation of an algorithm for Crohn's treatment, the strategy of early combined immunosuppression was equally effective and safe in older and younger patients, compared to conventional management; this strategy decreased the risks of surgery, hospitalization, and disease-related complications. ${ }^{28}$ Additionally, according to a recent pooled analysis of data from randomized trials, older patients with UC had no incremental risk of serious adverse events attributable to antiTNF therapy compared to younger patients. ${ }^{29}$ Moreover, a recent study reported that frailty, independent of age, was related with an increased infection risk after the administration of anti-TNF and immunomodulatory agents in patients with IBD, suggesting frailty rather than chronological age may provide a more comprehensive assessment of the infection risk. ${ }^{30}$

Another important finding of the current study is that 
corticosteroid use at diagnosis was associated with poor disease outcomes, including proximal disease extension and hospitalization, in patients with EOUC. This finding seems comparable with the findings of previous Western studies, in which corticosteroid dependency or the use of corticosteroids was associated with poor disease outcomes of UC, such as high surgery rates. ${ }^{18,25}$ According to a recent meta-analysis of Western population-based studies, more extensive disease and corticosteroid use were associated with an increased risk of colectomy in EOUC. ${ }^{17}$ However, the predictors associated with colectomy were not identified in this study probably due to the small number of events (i.e., only two cases underwent colectomy during the follow-up). As described in our previous report, Korean patients with UC showed a lower colectomy rate than Western patients. ${ }^{21}$

The current study has the following strength: this study used a population-based design in a well-established administrative region, which enabled us to include unselected patients representing the entire disease spectrum. Moreover, this study assessed the natural history of EOUC in a non-Caucasian population-based cohort; our findings may be used to develop evidence-based guidelines for the management of EOUC, specifically in Asian populations.

However, our study has some limitations. First, we could not investigate the impact of baseline disease activity on the UC outcome because data on UC disease activity at diagnosis and baseline laboratory results were not collected. Instead, we used the corticosteroid use at UC diagnosis as a surrogate marker of baseline disease activity. Second, we did not collect data on the comorbidities including malignancies and infections that may affect UC outcomes in this study. However, unlike the previous studies that reported a worse prognosis of EOUC than of N-EOUC, ${ }^{12-14}$ the results of the present study may suggest that EOUC does not have an aggressive disease course compared to that of N-EOUC despite the possibility of a higher burden of comorbidities in patients with EOUC than in those with N-EOUC. Third, whether the findings of this study can be generalized to other Asian populations remains unclear, considering that there are genotypic and phenotypical variations in IBD among Asian countries. ${ }^{31}$ Lastly, we could not evaluate the causality between therapy patterns and disease outcomes, including colectomy, in EOUC in this analysis.

In conclusion, the natural course and outcomes of EOUC seem to be comparable to those of N-EOUC, along with similar rates of the use of medications, including corticosteroids and disease-modifying drugs, at a population level in Korea. Moreover, the risk factors for disease outcomes in the EOUC group seem comparable to those in the Western population. By understanding the long-term clinical course of EOUC, we can manage this subset of patients with UC more appropriately and in a timely manner.

\section{CONFLICTS OF INTEREST}

S.K.Y. received a research grant from Janssen Korea. The remaining authors disclose no conflicts.

J.P.I. is an editorial board member of the journal but was not involved in the peer reviewer selection, evaluation, or decision process of this article. No other potential conflicts of interest relevant to this article were reported.

\section{ACKNOWLEDGEMENTS}

This work was partially supported by a Korean Health Technology R\&D Project grant from the Korea Health Industry Development Institute to S.K.Y. (A120176), funded by the Ministry of Health \& Welfare, and by a research grant from Janssen Korea.

The authors acknowledge Euiyoun Kang and Eun Ja Youn for their efforts regarding data abstraction.

\section{AUTHOR CONTRIBUTIONS}

Study concept and design: S.H.P., S.K.J., J.H.L., B.D.Y., S.K.Y. Acquisition of data: S.H.P., K.H.R., Y.H.K., S.N.H., K.H.K., S.I.S., J.M.C., S.Y.P., S.K.J., J.H.L., H.P., J.S.K., J.P.I., H.Y., S.H.K., J.J., J.H.K., S.O.S., Y.K.K., B.D.Y., S.K.Y. Statistical analysis and interpretation of data: S.H.P., B.D.Y., S.K.Y. Drafting of the manuscript: S.H.P., S.K.J., J.H.L., S.K.Y. Critical revision of the manuscript for important intellectual content: S.K.Y. Study supervision: S.K.Y.

\section{ORCID}

Sang Hyoung Park https://orcid.org/0000-0002-5366-5749 Seung Kyu Jeong https://orcid.org/0000-0002-6027-3719 Ji Hyun Lee https://orcid.org/0000-0001-9368-5739 Kyoung Hoon Rhee

https://orcid.org/0000-0001-5144-0135

Young-Ho Kim https://orcid.org/0000-0003-1803-2513

Sung Noh Hong https://orcid.org/0000-0002-4140-3717

Kyung Ho Kim https://orcid.org/0000-0002-9607-6258

Seung In Seo https://orcid.org/0000-0003-4417-0135

Jae Myung Cha https://orcid.org/0000-0001-9403-230X

Sun Yong Park https://orcid.org/0000-0002-8367-2587

Hyunju Park https://orcid.org/0000-0002-2017-7191 
Joo Sung Kim

Jong Pil Im

Hyuk Yoon

Sung Hoon Kim

Jisun Jang

Jeong Hwan Kim

Seong O Suh

Young Kyun Kim

Byong Duk Ye

Suk-Kyun Yang https://orcid.org/0000-0001-6835-4735

https://orcid.org/0000-0003-1584-0160

https://orcid.org/0000-0002-2657-0349

https://orcid.org/0000-0002-6412-9757

https://orcid.org/0000-0003-1469-8940

https://orcid.org/0000-0002-2503-2688

https://orcid.org/0000-0003-3727-7815

https://orcid.org/0000-0002-0384-1871

https://orcid.org/0000-0001-6647-6325

https://orcid.org/0000-0003-2772-2575

\section{REFERENCES}

1. Ungaro R, Mehandru S, Allen PB, Peyrin-Biroulet L, Colombel JF. Ulcerative colitis. Lancet 2017;389:1756-1770.

2. Aniwan S, Park SH, Loftus EV Jr. Epidemiology, natural history, and risk stratification of Crohn's disease. Gastroenterol Clin North Am 2017;46:463-480.

3. Coward S, Clement F, Benchimol EI, et al. Past and future burden of inflammatory bowel diseases based on modeling of population-based data. Gastroenterology 2019;156:13451353.

4. Park SH, Kim YJ, Rhee KH, et al. A 30-year trend analysis in the epidemiology of inflammatory bowel disease in the Songpa-Kangdong district of Seoul, Korea in 1986-2015. J Crohns Colitis 2019;13:1410-1417.

5. Lapidus A, Bernell O, Hellers G, Persson PG, Löfberg R. Incidence of Crohn's disease in Stockholm County 1955-1989. Gut 1997;41:480-486.

6. Benchimol EI, Manuel DG, Guttmann A, et al. Changing age demographics of inflammatory bowel disease in Ontario, Canada: a population-based cohort study of epidemiology trends. Inflamm Bowel Dis 2014;20:1761-1769.

7. Jeuring SF, van den Heuvel TR, Zeegers MP, et al. Epidemiology and long-term outcome of inflammatory bowel disease diagnosed at elderly age-an increasing distinct entity? Inflamm Bowel Dis 2016;22:1425-1434.

8. Ananthakrishnan AN, Shi HY, Tang W, et al. Systematic review and meta-analysis: phenotype and clinical outcomes of older-onset inflammatory bowel disease. J Crohns Colitis 2016;10:1224-1236.

9. Gisbert JP, Chaparro M. Systematic review with metaanalysis: inflammatory bowel disease in the elderly. Aliment Pharmacol Ther 2014;39:459-477.

10. Borren NZ, Ananthakrishnan AN. Safety of biologic therapy in older patients with immune-mediated diseases: a systematic review and meta-analysis. Clin Gastroenterol Hepatol 2019;17:1736-1743.

11. Lewis JD, Scott FI, Brensinger CM, et al. Increased mortality rates with prolonged corticosteroid therapy when com-

pared with antitumor necrosis factor- $\alpha$-directed therapy for inflammatory bowel disease. Am J Gastroenterol 2018;113:405-417.

12. Mañosa M, Calafat M, de Francisco R, et al. Phenotype and natural history of elderly onset inflammatory bowel disease: a multicentre, case-control study. Aliment Pharmacol Ther 2018;47:605-614.

13. Song EM, Lee HS, Park SH, et al. Clinical characteristics and long-term prognosis of elderly onset ulcerative colitis. J Gastroenterol Hepatol 2018;33:172-179.

14. Zammarchi I, Lanzarotto F, Cannatelli R, et al. Elderly-onset vs adult-onset ulcerative colitis: a different natural history? BMC Gastroenterol 2020;20:147.

15. Shi HY, Chan FK, Leung WK, et al. Natural history of elderly-onset ulcerative colitis: results from a territorywide inflammatory bowel disease registry. J Crohns Colitis 2016;10:176-185.

16. Mak JWY, Ho CLT, Wong K, et al. Epidemiology and natural history of elderly-onset inflammatory bowel disease: results from a territory-wide Hong Kong IBD registry. J Crohns Colitis 2021;15:401-408.

17. Rozich JJ, Dulai PS, Fumery M, Sandborn WJ, Singh S. Progression of elderly onset inflammatory bowel diseases: a systematic review and meta-analysis of population-based cohort studies. Clin Gastroenterol Hepatol 2020;18:2437-2447.

18. Charpentier C, Salleron J, Savoye G, et al. Natural history of elderly-onset inflammatory bowel disease: a populationbased cohort study. Gut 2014;63:423-432.

19. Lakatos PL, David G, Pandur T, et al. IBD in the elderly population: results from a population-based study in Western Hungary, 1977-2008. J Crohns Colitis 2011;5:5-13.

20. Loftus EV Jr, Silverstein MD, Sandborn WJ, Tremaine WJ, Harmsen WS, Zinsmeister AR. Ulcerative colitis in Olmsted County, Minnesota, 1940-1993: incidence, prevalence, and survival. Gut 2000;46:336-343.

21. Cha JM, Park SH, Rhee KH, et al. Long-term prognosis of ulcerative colitis and its temporal changes between 1986 and 2015 in a population-based cohort in the Songpa-Kangdong district of Seoul, Korea. Gut 2020;69:1432-1440.

22. Burisch J, Katsanos KH, Christodoulou DK, et al. Natural disease course of ulcerative colitis during the first five years of follow-up in a European population-based inception cohort-an Epi-IBD study. J Crohns Colitis 2019;13:198-208.

23. Jeuring SF, van den Heuvel TR, Liu LY, et al. Improvements in the long-term outcome of Crohn's disease over the past two decades and the relation to changes in medical management: results from the population-based IBDSL Cohort. Am J Gastroenterol 2017;112:325-336.

24. Ooi CJ, Hilmi I, Banerjee R, et al. Best practices on immunomodulators and biologic agents for ulcerative colitis and Crohn's disease in Asia. Intest Res 2019;17:285-310. 
25. Alexakis C, Saxena S, Chhaya V, Cecil E, Curcin V, Pollok $\mathrm{R}$. Do thiopurines reduce the risk of surgery in elderly onset inflammatory bowel disease? A 20-year national populationbased cohort study. Inflamm Bowel Dis 2017;23:672-680.

26. Everhov ÅH, Halfvarson J, Myrelid P, et al. Incidence and treatment of patients diagnosed with inflammatory bowel diseases at 60 years or older in Sweden. Gastroenterology 2018;154:518-528.

27. Fung BM, Perrault J, Tabibian JH. Ethnoracial, geographic, and socioeconomic disparities and variations in inflammatory bowel disease. Clin Gastroenterol Hepatol 2018;16:11761177.

28. Singh S, Stitt LW, Zou G, et al. Early combined immunosuppression may be effective and safe in older patients with Crohn's disease: post hoc analysis of REACT. Aliment Phar- macol Ther 2019;49:1188-1194.

29. Cheng D, Cushing KC, Cai T, Ananthakrishnan AN. Safety and efficacy of tumor necrosis factor antagonists in older patients with ulcerative colitis: patient-level pooled analysis of data from randomized trials. Clin Gastroenterol Hepatol 2021;19:939-946.

30. Kochar B, Cai W, Cagan A, Ananthakrishnan AN. Pretreatment frailty is independently associated with increased risk of infections after immunosuppression in patients with inflammatory bowel diseases. Gastroenterology 2020;158:2104-2111.

31. Thia KT, Loftus EV Jr, Sandborn WJ, Yang SK. An update on the epidemiology of inflammatory bowel disease in Asia. Am J Gastroenterol 2008;103:3167-3182. 